\title{
LA CIUDAD DE POPAYÁN, COLOMBIA, DESDE LOS IMAGINARIOS DE LOS JÓVENES MIGRANTES*
}

\author{
Harold Humberto Velasco Chávez \\ Licenciado en Educación básica con énfasis en educación física, \\ recreación y deporte. Universidad del Cauca, Colombia. \\ Estudiante de la Maestría en Educación, Línea comunicación \\ educación y cultura. Universidad del Cauca, Colombia. \\ Grupo de Investigación: Urdimbre. \\ haroldhvel@hotmail.com
}

\section{Cómo citar este artículo:}

Velasco, H. (2014). La ciudad de Popayán Colombia desde los imaginarios de los jóvenes migrantes. Espiral, Revista de Docencia e Investigación, 4(1), 31 - 48

\begin{abstract}
Resumen
El presente artículo de reflexión se origina en el seno de la Maestría en Educación de la Universidad del Cauca, cuya finalidad está planteada en desarrollar un proceso investigativo que para este caso ayude a la construcción de conocimiento alrededor de tres grandes unidades: jóvenes, imaginarios y ciudad, para así continuar comprendiendo las dinámicas en las que se mueve la praxis pedagógica y la realidad contextual y subjetiva de los individuos con los que día a día nos enfrentamos dentro de nuestro quehacer. Se realizó una revisión teórica de las categorías mencionadas. Por ello, el acercamiento metodológico se hizo desde una perspectiva cualitativa, edificada en una metodología de historia de vida que permitió una primera interpretación de la realidad y de los elementos circundantes, que construyen entramados de significaciones desde las "artes de hacer" propuestas por Michel De Certeau en dos categorías la "estrategia" y la "táctica". Los resultados obtenidos giran en torno al hallazgo elementos relacionados con la libertad de vivir en connivencia con una disputa interna entre lo propio del migrante y lo novedoso de la urbe, situación que los hace susceptibles a ser transformados, durante el proceso investigativo que se llevó a cabo en el barrio Bellohorizonte de la ciudad de Popayán, con algunos jóvenes que han migrado a ella.
\end{abstract}

Palabras clave: Ciudad, imaginarios, jóvenes, migración.

\footnotetext{
Abstract

This academic reflection originates within the Master of Education from the University of Cauca, whose purpose is posed to develop a research process for this case helps build knowledge around three outstanding items: young people, imaginary and city. In this way, we will continue understanding the dynamics in which the pedagogical praxis and contextual and subjective reality of indivi-
}

duals that we face every day in our daily life. A theoretical review of the above categories has been carried out. Therefore, the methodological approach was made from a quality perspective, based on a life history methodology that allowed a first interpretation of reality and of the surrounding elements, building patterns of meaning from the "arts of making" proposed by Michel De Certeau into two categories the "strategy" and "tactics", finding out some elements related to the freedom of living in coexistence with an internal dispute between the culture of migrants and the novelty elements of the city, a situation that makes them susceptible to be transformed during the investigative process that took place in a neighborhood called Bellohorizonte in Popayan, with some young people who have migrated to it.

Keywords: City, imaginaries, young people, migration.

\section{Introducción}

En la ciudad de Popayán podemos visibilizar diferentes maneras de vivir; sólo basta con recorrer sus calles, escuchar sus ruidos, sus olores, observar sus edificaciones y las personas que la transitan. Son precisamente estos sujetos jóvenes los que aparentemente la dotan de significaciones que la hacen identificable. Para sumergirnos en la realidad, nos aproximaremos a ella intentando comprender a las/los jóvenes a través de sus imaginarios de ciudad, de forma tal que nos permitan descubrir sus mundos interiores, sus formas de comunicarse, de vivir con los otros, con ellos mismos y con la ciudad. Hemos dirigido nuestras observaciones hacia las/los jóvenes que han migrado a la ciudad de Popayán por razones que se encuentran entre: 


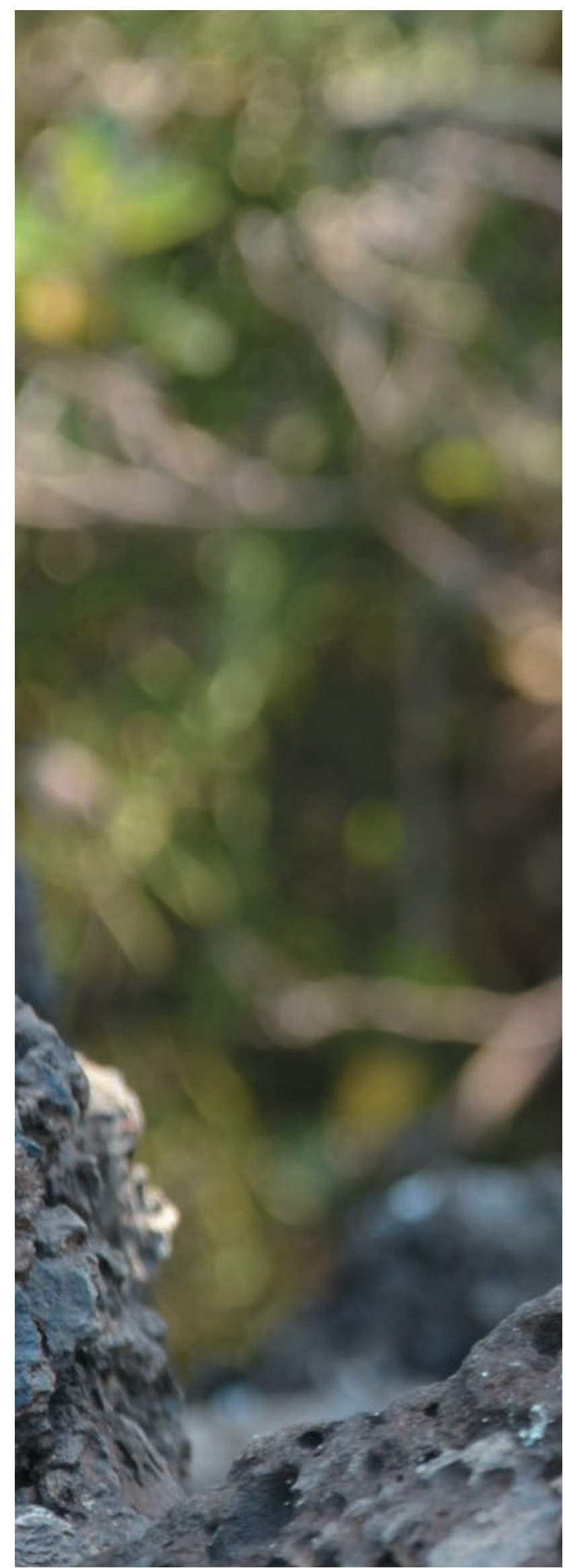

el flujo de jóvenes que vienen a adelantar estudios, el desplazamiento forzado, problemas de pobreza y desastres naturales, y también el éxodo que toca a grupos indígenas que se ven obligados a movilizarse a esta ciudad para comercializar sus productos de pan coger.

Este artículo se centra pues, en comprender a las/los jóvenes que han migrado a esta ciudad y moran al norte de Popayán en el barrio Bellohorizonte, y que por medio de sus itinerarios y trayectorias configuran sus imaginarios de ciudad, visibilizando la influencia que ellos tienen en la transformación de la ciudad que recorren, las situaciones que los trajeron aquí, el impacto que tienen en la ciudad, sus prácticas culturales y cómo estas han migrado con ellos, pero también dejando ver los problemas que los afectan: como las pocas opciones educativas, el desempleo, la escasa participación en la política pública, y cómo estos jóvenes se insertan activamente en las mutaciones de la ciudad, ya que cada uno de los actores socioculturales en sus diversos escenarios recrean imaginarios de ciudad.

Con lo anterior, surgen las siguientes preguntas: ¿De qué manera los jóvenes se relacionan en procesos educativos con la ciudad de Popayán? ¿Qué motivaciones trajeron a estos jóvenes migrantes a esta ciudad? ¿Cómo le aportan los jóvenes migrantes a la ciudad?

Además, dichas preguntas ayudaron en la construcción de un interrogante investigativo: ¿Cómo comprender los imaginarios de ciudad de los jóvenes migrantes del barrio Bellohorizonte de la ciudad de Popayán? Nos aproximamos a la pregunta de la siguiente manera: visibilizando a las/los jóvenes migrantes del barrio Bellohorizonte; en la comprensión de las motivaciones que los trajeron a la ciudad; la interpretación del impacto recibido; y el reconocimiento de las distintas maneras en que los jóvenes del barrio se agrupan en la ciudad. Es preciso ubicar al lector en el contexto del cual se desprenden los elementos con los cuales 
jóvenes migrantes han construido sus significaciones sociales, instaurando maneras en las que ellos y ellas establecen tácticas y estrategias para navegar en el mar de las situaciones sociales en las que han tenido que afrontar sus realidades.

\section{Ubiquémonos en contexto}

Popayán, capital del departamento del Cauca, se sitúa en el Valle de Pubenza, entre las cordilleras Occidental y Central de Colombia, con una extensión de 51.200 hectáreas, de las cuales el $95 \%$ es área rural; está ubicada a 1.737 $\mathrm{m}$ sobre el nivel del mar, y tiene un promedio de $29^{\circ} \mathrm{C}$ de temperatura; cuenta con aproximadamente 258.653 habitantes. La ciudad se distribuye en nueve comunas (área urbana), y para el caso de este estudio es relevante la comuna dos, la cual presenta el mayor número de barrios, (sesenta). En relación a las demás, que contienen 33.759 pobladores, o sea el 13,05\% de la población total, el 13,82\% corresponde al barrio Bellohorizonte, siendo la más alta concentración poblacional en comparación a los demás barrios de la comuna. Además, es uno de los más antiguos y pertenece al estrato 2 (Alcaldía de Popayán 2012).

Durante el recorrido por Bellohorizonte confirmamos que el barrio cuenta con un hospital de nivel uno, una plaza de mercado, una estación de policía, seis templos religiosos, tres parques, cinco colegios, veintitrés salas de internet y cinco salas de videojuegos, lo que le permite a sus habitantes encontrar todo a corta distancia y migrar hacia él.

Al indagar sobre las causas de estas migraciones encontramos: el flujo de jóvenes que vienen a adelantar estudios en los diferentes niveles educativos, por ello es común hallar coIonias de Nariño, Huila, Valle del Cauca, Guapi, Timbiquí, y de la costa Caribe Colombiana. Otro factor es el desplazamiento forzado Conviene aclarar aquí la dimensión de este fenómeno social consecuencia del conflicto interno colombiano:
Es desplazada toda persona que se ha visto forzada a migrar dentro del territorio nacional abandonando su localidad de residencia o actividades económicas habituales, porque su vida, su integridad física, su seguridad o libertad personales han sido vulneradas o se encuentran directamente amenazadas, con ocasión de cualquiera de las siguientes situaciones: conflicto armado interno, disturbios y tensiones interiores, violencia generalizada, violaciones masivas de los derechos humanos, infracciones al derecho internacional humanitario $u$ otras circunstancias emanadas de las situaciones anteriores que puedan alterar o alteren drásticamente el orden público. Artículo 1 LEY 387 de 1997.

Ante esto, conviene agregar respaldados por el Boletín de consultoría para los derechos humanos y el desplazamiento CODHES que, según datos, entre el año 1999 y el 2010 al Cauca Ilegaron un total de 155.264 personas en condición de desplazados, de los cuales $38,8 \%$ arribaron a la ciudad de Popayán (60.356 personas) y que para el primer semestre del año 2011 el Cauca hizo parte de los cinco primeros departamentos, con un total de 4.957 personas llegadas. Además, están los desastres naturales que, como el terremoto ocurrido en la ciudad en 1983, atrajo migrantes aprovechando la situación de desastre, lo que hizo que la ciudad se expandiera; como lo expresa Tocancipá (2006) la ciudad posterior al terremoto pasa de poseer 28 barrios a más de 273 en los veinte años siguientes y en el año 1994, una avalancha en la región de Tierradentro, al oriente del departamento del Cauca, desencadenó el desplazamiento que dio origen al barrio Tóez, que también hace parte de la comuna dos. Es necesario mencionar el éxodo que toca a grupos indígenas que se desplazan a esta ciudad para comercializar sus productos en plazas de mercado, andenes y semáforos, o simplemente en el comercio ambulante. 
Las cifras del Departamento Administrativo Nacional de Estadística (DANE) cuyos valores negativos hacen referencia a personas que salen del departamento, demuestran que los flujos migratorios para el departamento del Cauca entre los años 2000 y 2005 son de -6.175 hombres y de -8.565 mujeres entre los 15 y 24 años de edad, valores que permiten apreciar la relevancia de la migración a nivel del departamento. Y en cuanto a los datos de jóvenes en Colombia para el año 2005 por grupo étnico son: de 337.199 indígenas, con un 24,21\%; y de afro-colombianos con 1.081.517, para el 25,08\%; y los desplazamientos de jóvenes de zonas rurales por educación fueron: 1.488 hombres, para un 27,9\%, y 1.214 mujeres, un $25,7 \%$, entre 15 a 29 años. Lo que indica la importancia de los afrodescendientes y los indígenas como agentes que movilizan su cultura, contribuyendo así a la configuración de la ciudad de Popayán. Aunque se presente la dificultad de no encontrar registros estadísticos de los anteriores aspectos a nivel del barrio Bellohorizonte, se pretende establecer aproximaciones que permitan identificar la realidad de la migración en dicho barrio, todo esto reconociendo su historia como lo expresa Daza (2010).

Aquella extensa llanura que hoy es el BeIlohorizonte, fue propiedad de Álvaro Pio Valencia (hijo del poeta Guillermo Valencia), quien con el ánimo de contribuir a una solución de vivienda entre algunos de los habitantes de la ciudad de Popayán, inicia el proceso de parcelación del terreno en el año de 1960, parcelación de la que saldrían beneficiadas muchas personas de escasos recursos, pues estos lotes fueron vendidos a módicas cuotas y sin intereses (pp. 2-3).

Además, apoya, para esto, la información que continuamente generan los informantes en sus diferentes espacios de encuentro, la cual gira alrededor de la idea de que a través de los años este barrio ha ido expandiéndose hasta donde le han permitido sus vecinos, nu- triéndose de diversas gentes que han ido llegando desde aquí y allá. Las cifras y la historia nos exponen elementos de valor para resaltar la importancia del fenómeno migratorio y su validez para pensar la ciudad de Popayán a través de los imaginarios de los jóvenes venidos a ella.

\section{La teoría formal}

En este aparte se realiza una reflexión concienzuda de los tres ejes fundamentales en los que se soportan las ideas aquí expuestas, estos son: jóvenes, imaginarios y ciudad, así como también elementos que se encuentran en directa relación con los mismos, de la siguiente manera:

\section{Jóvenes a través de la historia}

Ubicarnos conceptualmente en la denominación de "jóvenes" en la sociedad contemporánea implica recopilar distinciones desde diferentes disciplinas que, a través de la historia, han venido estudiando los teóricos. Así, Hurtado (2011), plantea desde la psicología del desarrollo en relación con la adolescencia, la sociología enfocada al concepto de desviación, el discurso jurídico desde la criminalización, y la industria cultural y las culturas juveniles a partir de la otredad. Estos modos de referirse a ellos busca diferenciarlos del niño y del adulto, como tiempo en el que se adquieren las herramientas necesarias para convertirse en adulto e insertarse en la sociedad; a esto, Margulis y Urristi (1998) denomina moratoria social, y Carles Feixa (1999) los define en cinco modelos de juventud: "púberes" (sociedades primitivas), "efebos" (estados antiguos), "mozos" (sociedades campesinas preindustriales), "muchachos" (primera industrialización), y "jóvenes" (sociedades posindustriales). De esta manera apreciamos cómo el concepto cambia por el lugar de enunciación y por las necesidades sociales y económicas de cada tiempo.

En la actualidad, uno de los elementos relacionados con la juventud es el de moratoria social, que para Feixa (1999) y Hurtado (2011) es 
entendido como un periodo en el que los jóvenes asumen un tiempo marcado por el aprendizaje escolar y el ocio creativo, una construcción social asociada a la escolaridad, a postergar el ingreso a la vida laboral de aquellos que pueden acceder a ella; pero también los jóvenes instauran formas de establecer su propia moratoria, lo que nos permitiría adentrarnos en sus realidades, como posibilidad de configuración de sus propios imaginarios.

\section{La categoría juventud}

El ser joven ha estado sometido a representaciones y significaciones que a través del tiempo y de su contexto han ido cambiando. Estas, de acuerdo al Instituto de Estudios Peruanos (2002) son casi tangibles, circulan, se cruzan y se cristalizan en lo cotidiano a través de una palabra, un gesto, un encuentro; constituyen, en definitiva, una de las vías para captar el mundo concreto. De esta manera los autores Castellanos (2011), Martínez (2011), Feixa (1999) y Margulis y Urresti (1998) comparten la idea de que la juventud es una condición diferenciable con características modificadas en el tiempo y en su lugar de enunciación.

Plantea Castellanos (2011) que la juventud está combinada por productores de diversidad social como el género, la etnicidad y la clase social, que nos permiten realizar una aproximación a la categoría, ya que ésta es el resultado de la construcción teórica y metodológica que las ciencias sociales han realizado. Partiendo de esto, Castellanos (2011) propone dos opciones de acercamiento a la categoría juventud: una en la que sean visibles las prenociones en sus palabras, la "doxa"; y la otra entreteje la categoría en el sistema de relaciones sociales, en lo cual está de acuerdo con Martínez (2011), quien lo hace desde la relación juventud-subjetividad, mediada temporal y contextualmente, partiendo de lo conocido, de lo cercano para llegar a lo desconocido, lo que se puede descubrir, logrando construir nuevos planteamientos que problematicen el concepto de juventud.
Los elementos a tener en cuenta, a juicio de Castellanos (2011), se mueven entre: los tránsitos de etapa niñez-adolescencia, lo masculino y lo femenino, las trayectorias posibles y deseables de los sujetos, las demandas del sistema de producción, la clase social, la condición étnica, y un imaginario que les predispone a un estado de inexperiencia, momento de poco prestigio, de poco poder y debilidad, comprendiendo así sus diferencias. Pero a la par de esto, se reconoce una capacidad de creación desde su subjetividad. De tal suerte plantea Martínez (2011) que al ser jóvenes tienen la posibilidad de fortalecer sus potencialidades y construir su identidad, no la masificada en los medios de comunicación o en las instituciones sociales, que mediante sus mecanismos de poder los influyen, y éstos los jóvenes- hacen resistencia, como lo plantea Martínez (2011) retomando el concepto de multitud para referirse a esta categoría:

El conjunto de singularidades que son un sujeto social, cuya diferencia no puede dirigirse a uniformidad; es decir, una multiplicidad que permite la diferencia. La juventud por su parte es una categoría que también es singularidad y, como la multitud, es pluralidad que permite la diferencia (p.213).

El sujeto de la juventud tiene connotaciones que atraviesan el plano físico, el estético, el político, pasando por su accionar en la sociedad de consumo, un momento en el que se vive, en el que está situado. De esta manera se le han atribuido a la juventud unos imaginarios instituidos que al decir de Castoriadis (1992) representan la propia obra de la sociedad a partir del momento en que un colectivo humano crea un lenguaje, construye creencias, leyes y valores para orientar su vida. Esta etapa es pues, definida según el juicio de Hurtado (2004), como etapa de transición: marcada por el concepto de ciclo vital y moratoria social; como periodo de crisis: sujetos en riesgo estigmatizados por la sociedad, y como actores estratégicos del desarroIlo: esperanza de cambio de la realidad social. Lo 


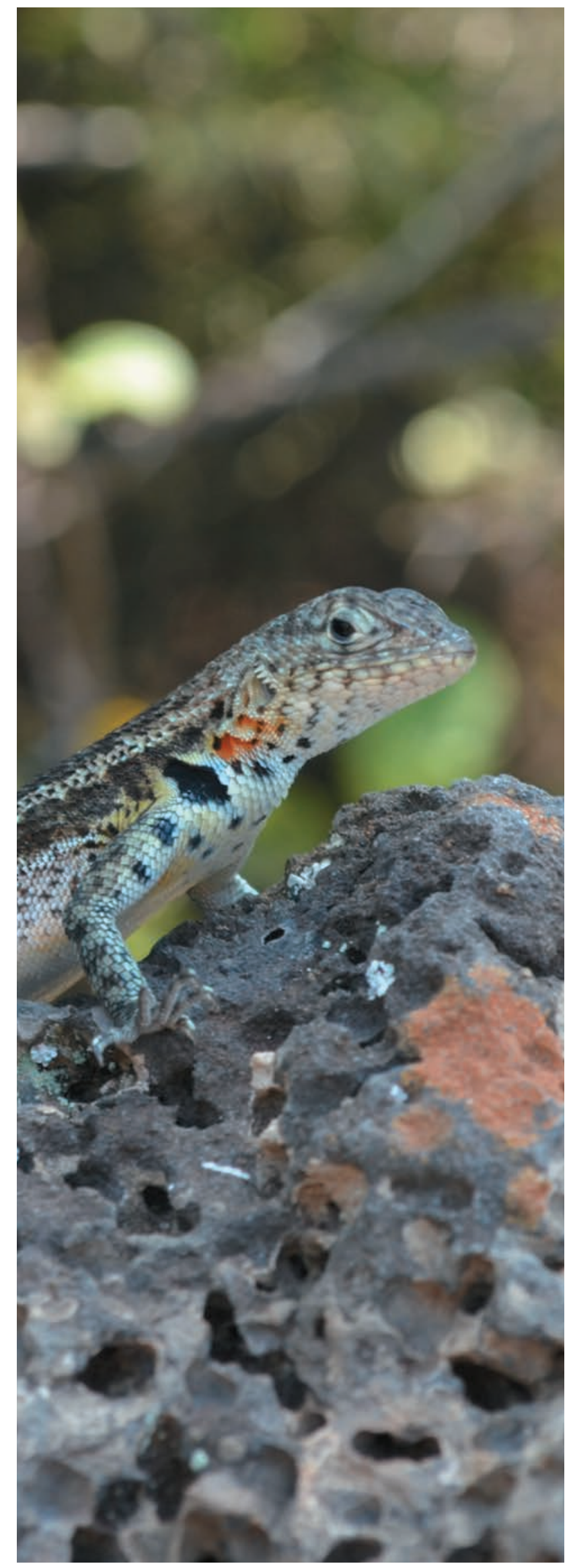

anterior, entreteje formas de definir la juventud; el ser joven pasa de lo incompleto a lo posible, de lo marginal a lo esperanzador, como lo denomina Margulis y Urresti (1998): el "joven del mito", como estereotipo que implanta los significantes consumistas, ser joven es prestigioso, como un estado placentero que quienes lo disfrutan pretenden eternizar, idealizando un período de poder, de confianza, de lograrlo todo, de vencer obstáculos y de alcanzar las metas, de llegar a ser todo lo que se quiere ser y de no encontrar límites aparentes.

Estos argumentos de juventud, como afirma Hurtado (2004), se presentan como imaginarios instituidos por la sociedad de consumo, construyendo un velo que no permite apreciar a un joven como lo plantea él mismo y Martínez (2011); que desde su estética, su dimensión cultural crea otras formas de representarse, otras formas de ser, entramados de significaciones que lo hacen relacionarse de formas diferentes con los demás y con la ciudad que habitan. Planteamientos que resultan valiosos para comprender cómo los jóvenes migrantes se relacionan, se viven, se transforman con y en Popayán, cómo ellos configuran nuevos significados, nuevos lenguajes, nuevas formas de transitar la ciudad; en fin, sus imaginarios de ciudad.

\section{Juvenilización}

La juvenilización, desde el planteamiento de Hurtado (2011), se expresa como "el culto a lo joven" (p.32) y Margulis y Urresti (1998) la señalan como el cúmulo de signos que pasan el contexto particular de la actualidad, en el cual la imagen y la exaltación de lo juvenil en la sociedad de consumo genera una "encrucijada epocal" y una "moda de la juvenilización", las cuales propician el surgimiento de acciones encaminadas a que los sujetos no vivan su propia temporalidad, en una búsqueda de un cuerpo inalterable, en la cual, el culto a la imagen, a los consumos propios de los llamados jóvenes, sean lo primordial para eternizarse en esta denominación. 
Además, al denominar a un individuo como joven no podemos generalizar el conjunto de prácticas sociales en las que se desarrolla o las maneras en las que sus entramados de significaciones se construyen, como lo demuestra Hurtado (2011) “hay que superar la mirada de la juventud como un todo homogéneo, que desconoce las múltiples y variadas formas como ellas y ellos se vivencian como jóvenes de acuerdo con sus particulares condiciones de vida" (p.30). Además, este mismo autor, citando a Rosana Reguillo, se refiere a que los jóvenes como categoría social no tienen una existencia autónoma y se hace necesario para su compresión un análisis que apunte a concebirlos como sujetos sociales, desde un abordaje empírico de la juventud, actualizando subjetivamente a los sujetos concretos, lo que es acorde con el planteamiento de Castellanos (2011), cuando afirma que: "La producción de la juventud como objeto de conocimiento ha implicado la producción de algunos sujetos categorizados como juveniles, mediante dispositivos de clasificación biológica, psicológica, demográfica y política. Esto no produce jóvenes, sino sujetos en condición juvenil" (p.172). Comprendiendo que es el resultado de relaciones históricas -en lo que está de acuerdo Martínez (2011) — , entretejido en tramas de significados, en una sustancia de relaciones de poder, en la "diversidad social" que refiere a un estado de la persona, a una aptitud o a una disposición de ella ante la vida. Es desde estos planteamientos desde donde es plausible el abordaje teórico que se pretende hacer a los jóvenes del barrio Bellohorizonte de la ciudad de Popayán, que por múltiples razones han llegado a él y que de manera constante influencian la realidad social de esta ciudad.

\section{Jóvenes que habitan y los habita la ciudad, jó- venes en su territorio}

Descubrir al joven de este tiempo pasa por elementos propios de su cultura, de su manera de ser sujeto comunicativo, de su accionar político, de las formas en que se apropia de los sitios que recorre, de elementos tanto propios como

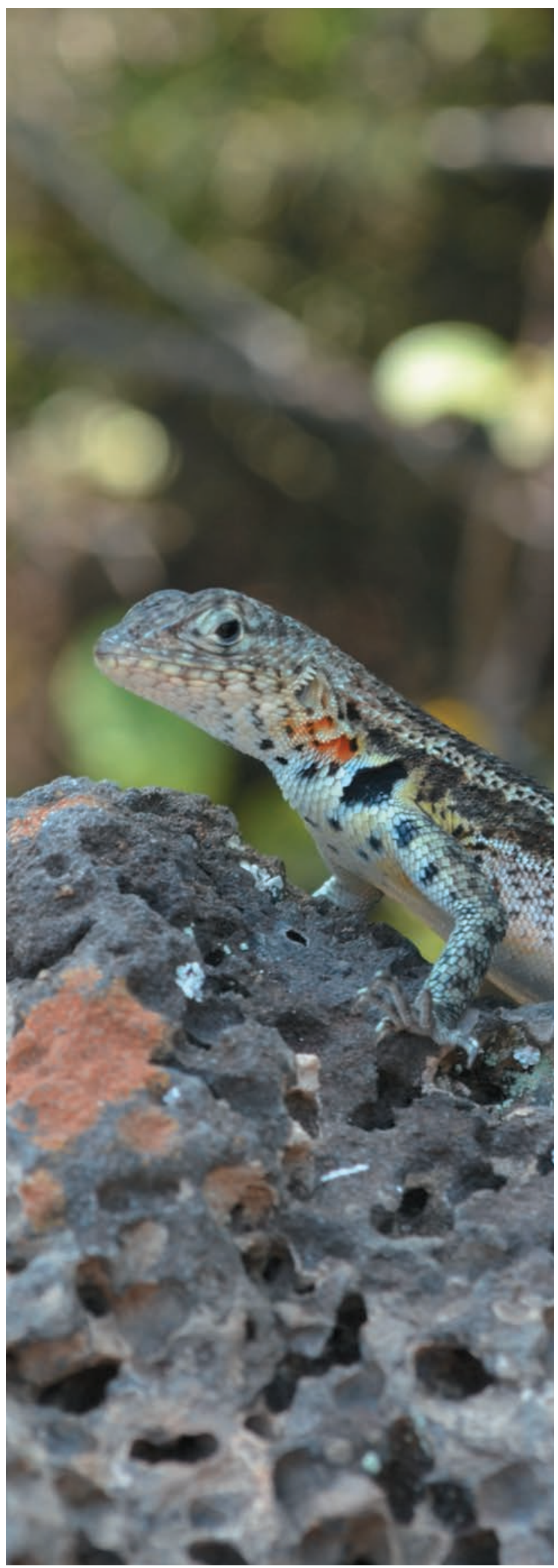


ajenos que lo modelan en su cuerpo, en sus imaginarios, en lo que es y quiere ser. Como lo menciona Buendía (2006) "en el espacio habitado y dotado de significación confluyen una serie de elementos físicos, históricos, sociales y estéticos que, compactados, forman y re-crean lo que hoy en días llamamos ciudad" (p.39). Además, el joven que habita la ciudad genera, por medio de sus tránsitos, otras prácticas diferentes a las evidentes, como lo plantea Muñoz (2011).

A los jóvenes y las jóvenes se les vea(sic) como agentes culturalmente activos, es decir, como personas que asumen su auto creación y la construcción de prácticas de libertad y de formas aceptables de existencia en el entorno más cercano, el de ciudadanías juveniles que permiten entrever una ciudadanía comunitaria (p.47).

Y es desde esta ciudadanía juvenil que se dirige la mirada a la relación de las/los jóvenes que aprenden en la ciudad y aprenden la ciudad, dos de las tres distinciones con las que Trilla (1993) se refiere a una ciudad educativa. En la primera el espacio provee el encuentro de diversos procesos educativos (en niveles formales, no formales e informales) y hacen referencia a educaciones de tipo formal: organizada por grados y otorga título; no formal: formación técnica para oficios, e informal: con los pares, en la calle, por los medios de comunicación Vasco (1997). Todo ello en una interacción que no sólo es la suma de los diversos elementos parciales, sino también la acción combinada de ellos.

La segunda hace referencia al "conocimiento informal que genera el medio urbano y es también conocimiento sobre el propio medio" (Trilla, 1993, p.187), a lo que Freire (1988) denomina "discursos de ciudad", es decir:

(...) el lenguaje popular contiene la sabiduría popular representada en los saberes de cada individuo; solo así podremos educar sin desconocer, sin minimizar, sin agredir a nuestros educandos, reconociendo en ellos su identidad tanto individual como colectiva, y su formación de la ciudadanía (p. 23).

Por tanto se aprende de ella, entendiendo la urbe no como objeto estático, sino capaz de evolucionar en una acción en la que las/los jóvenes participan en su construcción, en espacios que varían entre lo institucional y lo no institucional, entre quien enseña y a quien se enseña, todo en continua complementación u oposición. Planteamientos que tienen directa relación con lo dicho por Barbero (2002), quien lo define como "el componente pedagógico", el cual toma fuerza al reconocer los saberes perdidos, opacados y difusos, que son desconocidos por palabras en tonos más fuertes que presionan el lenguaje auténtico, simple y disiente de quienes ocultos en la multitud de los procesos de globalización, no alcanzan a exhalar la verdad de su ser.

En consecuencia, el ciudadano juvenil habita y es habitado; como indica Muñoz (2011), se mueve como agente culturalmente activo, sujeto con una impronta cultural histórica que lo define y predispone en su interacción con la urbe. Surgen así nuevas formas de ser joven un tanto globalizantes que llevan a transversalizar la realidad de un espacio determinado con la realidad del mundo: "las masas, con ayuda de las técnicas, hasta las cosas más lejanas y más sagradas las sienten cerca. $Y$ ese 'sentir', esa experiencia, tiene un contenido de exigencias igualitarias que son la energía presente de la masa" (Martín, 1987). Por tal razón, habitar la ciudad va más allá del simple hecho de recorrer sus calles, de ocupar sus espacios, de interactuar con los demás; es un proceso mediado por las tecnologías que, al relacionarse con los componentes comunicativos y educativos propios de la urbe, emergen estrategias de conocimiento que atraen a los jóvenes, posibilitando múltiples relaciones que dotan al individuo de nuevas herramientas, nuevas formas de ver el mundo, dando origen a procesos significativos con sus pares y con la ciudad, que lo hacen apropiarse de los espacios. 
Sujetos creadores de su propia espacialidad, que según (Ulloa, 2000)

Se refiere al espacio visto como escenario de la historia, activo en la construcción de la realidad y en los procesos de interacción social. Es la objetivación de los discursos y las ideologías que prevalecen en un momento determinado. Retomando las relaciones sociales y espaciales de forma interdependiente, a tal punto que el espacio posee una forma, una función y un significado (p.74).

Desde esta especialidad podemos comprenderlos porque constituyen sitios de intercambio, de encuentro en los que de acuerdo a Escobar, D., Ortega R., y Velasco H. (2007).

La creación de espacios de encuentro no solamente es de espacios físicos; es también de producción escrita y musical, de producción radial y de televisión, de foros y tertulias, de puestas en escena y de expresiones corporales. Haciendo posible el encuentro con sus pares, la expresión de sus ideas, la materialización de sus deseos y la construcción constante de su identidad (p. 124).

Espacios en los que las narraciones de ciudad emergen y sus procesos de participación ciudadana aparecen en sus itinerarios o recorridos por la ciudad que hacen referencia a desplazamientos propios del trabajo, del estudio, del mercado y los servicios, rutas más o menos fijas, temporalidades fijas (Ulloa, 2000, p.87). O trayectorias que hacen referencia a desplazamientos fortuitos, coyunturales 0 eventuales, haciendo distinción a rutas menos predecibles (Ulloa, 2000, p.88).

De ahí que como afirma Reguillo (1995) "la ciudad nos plantea no sólo la importancia comunicativa del espacio sino del tiempo: de la memoria y de las acrónicas, los destiempo y la necesidad (jbenjaminiana!) de liberar el pasado" (p.112). Pero debemos situarlos en una sociedad con características propias de nuestro país, del Cauca y de Popayán, entendiendo la relación entre jóvenes, sus imaginarios y la ciudad, como lo plantea Hurtado (2011) refiriéndose a la relación de los jóvenes con la ciudad de Popayán:

La ciudad que en ocasiones los invisibiliza y les niega sus espacios, de las cada vez más restringidas oportunidades que se les ofrecen. Es un intento por ser jóvenes en una ciudad vieja y predominantemente católica, una forma por re-configurar la ciudad con los usos que ellos le dan, de descentrarla, de llenar de colores la Ciudad Blanca mediante sus prácticas; y también una forma de resistencia a la pretensión de homogenizar los mundos de la vida juvenil y al mismo tiempo una forma de escapar, de negarse a ser víctimas y victimarios de la violencia (pp. 214-215).

La ciudad es el ambiente que ellos y ellas vuelven suyo, es el espacio urbano concebido al decir de Ulloa (2000) como:

El resultado de la relación dialéctica entre la ciudad que habitamos y la ciudad que nos habita. (...) Lo urbano, en este caso, se refiere a la relación entre espacialidad, definida antes y los sujetos sociales: o dicho de otro modo, lo urbano expresa las representaciones individuales de la espacialidad o del espacio socialmente construido" (Ulloa, 2000, p.77).

Lo urbano que impregna su olor, su ruido, su sensación, un nicho del que se apropian, y lo vuelven piel, lo hacen cuerpo, su cuerpo, su territorio, como lo argumenta Buendía (2006) al afirmar que la ciudad es espacio físico y simbólico, a la cual se le dota de significado dejando de ser simple lugar construido y habitado por humanos y se convierte en territorio; y Ulloa (2000) plantea que: "La experiencia cotidiana de las gentes carga de sentido a la ciudad con otros valores y otras connotaciones distintas a las lógicas por las cuales ella fue planificada y construida" (p.86). Pero al mismo tiempo los jóvenes cambian, modifican la situación que 
va más allá del ordenamiento físico, de las imágenes, de las cosas, de los espacios, de aquello que es público y de lo que es privado.

\section{Jóvenes migrantes o desplazados}

Por factores sociales, políticos, económicos, naturales, familiares, entre otros, grupos de personas se ven abocados a migrar de forma voluntaria. De tal suerte que surgen

movimientos hechos en el espacio, dotados de una significación para las personas, importantes en la construcción de la ciudad moderna y en la conformación de sus estructuras sociales y de sus ambientes culturales. En cuyo caso las ciudades no perecen por la migración, sino que cambian (Portes, 2001, p. 56).

Vale aclarar que cambian de sitio de residencia por culpa del desplazamiento forzado, como lo hace visible el CICR (2012) al mencionar que entre las causas de estos desplazamientos se encuentran las amenazas, el fuego cruzado, el asesinato de algún familiar, la violencia sexual $y$ el reclutamiento de menores, ocasionando que personas, familias y comunidades huyan para protegerse; además registra que para el año 2011 el Cauca es el máximo expulsor, con 9.760 personas reportadas, cuyos municipios con niveles más alarmantes fueron: Argelia, El Tambo, Suárez y Bolívar. Sumada a esta información, otros de los departamentos que aparecen en este informe son Antioquia, Caquetá, Nariño y Putumayo. Estos dos últimos limitan con el Cauca, y de ellos este departamento recibe desplazados.

Razones que demuestran cómo las personas se movilizan, en especial hacia las ciudades capitales, en las cuales aparentemente se presenta una mayor oferta de posibilidades educativas, laborales, de atención en salud y de obtención de tranquilidad, como lo menciona Portes (2001) "Tanto antes como ahora los medios urbanos atraen con el señuelo de la oportunidad económica, lo novedoso y el escape de rutinas paralizantes y opresivas" (p.115). A esta situación no son ajenos algunos jóvenes de la ciudad de Popayán, que deben afrontar el reto de desenvolverse en un espacio urbano y configurar otra ciudad, una ciudad para identificarse, una que remodelan y transforman, como lo expone Buendía (2006) "Quienes habitan la ciudad son transformados por ésta, al tiempo que ejercen sobre ella una dinámica transformadora que la construye al darle sentido" (p.38). La ciudad es el resultado de muchas partes, piezas venidas de diversos sitios, como lo corrobora (Ulloa, 2000, p.81): "La expansión física de la urbe, el crecimiento demográfico, los éxodos y las migraciones, han multiplicado las percepciones y las representaciones, fragmentadas y dispersas, pero también yuxtapuestas de la urbe actual". Todas estas situaciones hacen que los imaginarios que construyen estos migrantes sean valiosos para determinar en realidad ¿cómo viven a Popayán?, ¿qué es Popayán para ellos y ellas? y ¿cómo la definen?, preguntas que desde la diferencia de estos jóvenes, podemos responder.

\section{Metodología}

\section{Tipo de estudio}

Para entender la relación entre imaginarios de ciudad y jóvenes migrantes, debemos enmarcarla en la investigación social. Al pretender dar cuenta de los procesos que se suscitan entre los actores sociales, para este caso jóvenes migrantes que moran en el barrio Bellohorizonte de Popayán, y los elementos circundantes que construyen entramados de significaciones. La investigación se ubica desde una perspectiva cualitativa que facilita acercarnos a los imaginarios de ciudad de los jóvenes, permitiéndonos dar cuenta de una realidad que revela su indiscutible importancia; en tal sentido se plantea:

La metodología cualitativa consiste en más que un conjunto de técnicas para recoger datos: es un modo de encarar el mundo de la interioridad de los sujetos sociales y de las relaciones que establecen con los con- 
textos y con otros actores sociales. (Galeano, 2008, p.16)

Esta relación entre contexto y actor social se hace evidente entre ciudad, barrio y jóvenes; además, este tipo de investigación, de manera flexible y asincrónica posibilita construir conocimiento desde diversas disciplinas, desde la revisión a la "teoría formal" anteriormente expuesta, y el acercamiento a algunos jóvenes que habitan el barrio Bellohorizonte, "teoría sustantiva", facilitando conocer las realidades subjetivas e intersubjetivas de los actores sociales, pero confieren también la importancia de ubicar a los sujetos en relación con su concepto, como lo dice Restrepo (2002).

Es cierto que la investigación cualitativa goza de gran libertad frente al diseño y que éste se va armando a lo largo del desarrollo de la investigación; pero, una decisión frente al tipo de tradición por seguir confiere al proyecto, teorías de apoyo sobre la naturaleza del hombre y la sociedad, temáticas centrales de estudios previos que pueden ser utilizados como referencia y técnicas desarrolladas por la tradición en cuestión (p.131).

Por lo tanto, la investigación cualitativa permite interpretar la realidad como efecto histórico que posibilita la construcción de imaginarios a partir de las lógicas de sus protagonistas, con un enfoque interno que rescata la diversidad, encaminado a la comprensión del sujeto, su vivencia, y la interacción de los actores de la investigación.

\section{La historia de vida}

En cuanto a la selección del tipo de diseño, Galeano (2008) afirma: "Lo propio de los diseños cualitativos es combinar estrategias y modalidades de investigación de acuerdo al objeto de estudio, a la naturaleza y sentido de la pregunta, a las condiciones en que se desarrolla la misma" (p.30). En esta idea lo adecuado es permitir que los elementos consignados en este documento posibiliten la escogencia del

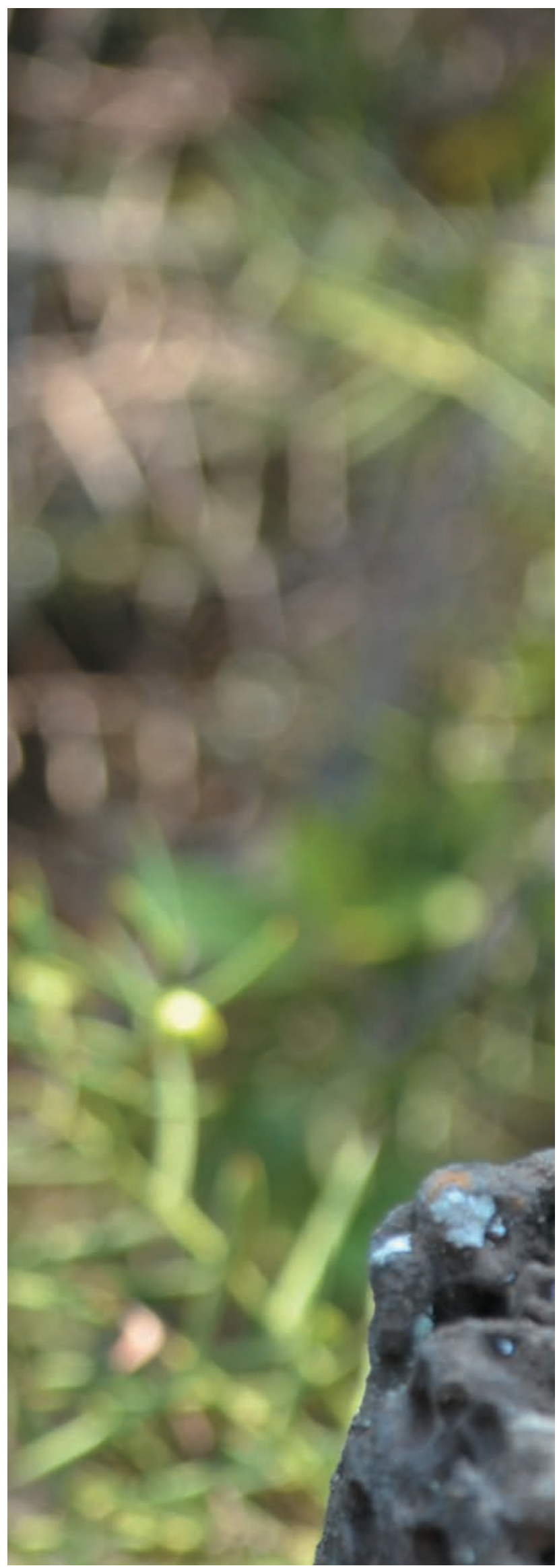


tipo de diseño, emergiendo, como una apropiada apuesta metodológica, la historia de vida como camino que facilita la reconstrucción de vivencias personales para comprender los imaginarios de los jóvenes migrantes en relación con la ciudad de Popayán, entrelazando el tiempo individual con el tiempo grupal, ya que la historia de vida:

Permite reconstruir los principales elementos del ciclo vital en relación con el tiempo social, esto es, contextualizado en una época histórica donde vive el protagonista; [...] expresar la permanente interacción entre la historia personal y la historia social y recrear con finos detalles y matices la riqueza de lo social en su complejidad (Galeano, 2008, p.63).

Además visibiliza percepciones, emociones, tradiciones, modos de vida e imaginarios, como conciencia reflexiva de los jóvenes que, de forma significativa, nos ayuda avanzar en la conceptualización del fenómeno de las migraciones en Popayán.

\section{Diseño metodológico}

Este acercamiento se realiza en tres momentos, como lo propone Galeano (2008): el "exploratorio", que hace referencia al acercamiento al ambiente social del barrio Bellohorizonte, en el cual se identificaron sitios de encuentro como parques, canchas de fútbol y tiendas de barrio, donde se aplicaron observaciones participantes, y además se contactaron jóvenes con las características requeridas. Posteriormente, y después de haber ubicado los jóvenes protagonistas o informantes, se continúa con el segundo momento, o "descripción", en el que se reconoce el contexto del cual provienen, y en el cual se adelantan entrevistas semi-estructuradas y en profundidad, las cuales permitieron indagar en las historias, las vidas e imaginarios de los jóvenes migrantes. $Y$ un tercero, que hace alusión al "análisis" que permite pasar de la reflexión concreta a la reflexión teórica, proceso que ha originado una primera interpretación de sentido.

Por lo anterior, las técnicas de recolección de información son: la observación participante, la entrevista semi-estructurada y en profundidad, las cuales son utilizadas de acuerdo a un plan de trabajo de campo con los sujetos participantes, que son aquellos jóvenes, hombres y mujeres en moratoria social, que han migrado a la ciudad de Popayán no hace menos de tres años, y que en la actualidad residen en el barrio Bellohorizonte.

\section{Aproximación a la interpretación de sentido}

Los recorridos investigativos han permitido ubicar jóvenes que viven en el barrio Bellohorizonte o que adelantan actividades en dicho sector; se han reconocido lugares recreativos en los que convergen, como parques, canchas de fútbol, tiendas del barrio y hasta una peluquería. Se han identificado esos espacios de encuentro como escenarios de subjetivación; además de grupos juveniles afiliados a fundaciones sociales como "Bandera joven", o a grupos religiosos de diferentes creencias que se reúnen en los seis templos religiosos que están ubicados en dicho barrio. Conviene aclarar que Bandera joven es una propuesta que surge en el año 2006, como espacio integrador de la comunidad con los jóvenes envueltos en violencia y drogadicción en los barrios aledaños a la parroquia la Sagrada Familia la cual se encuentra ubicada en el barrio Bellohorizonte. Bandera joven se propuso unir esfuerzos de diferentes instituciones y personas interesadas en el bienestar de la comunidad, es una propuesta que busca ubicar a los jóvenes en entornos libres de violencia, a partir de estrategias lúdicas, pastorales, educativas, sicosociales, artísticas y educativas descubriendo y aprovechando sus habilidades.

Lo anterior nos permite plantear que son las relaciones sociales, como lo menciona De Certeau (2000) las que determinan sus términos. 
Es complejo marcar su camino, en esta idea el proceso investigativo ha debido adecuarse a las dinámicas de determinadas agrupaciones que de forma programada o inesperada realizan encuentros en los que, como acertadamente lo expone el autor, se debe poner atención al acto de hablar, porque lo que se habla se vuelve realidad, una realidad que al ser discurso hace de su subjetivación un proceso colectivo que sueltan los informantes espontáneamente y que sólo en la intimidad de su cotidianidad y de sus relaciones de poder es posible comprender, ya que sólo en la práctica misma de la vida cotidiana reconoceremos sus imaginarios de ciudad.

En esta idea los primeros acercamientos a estos jóvenes se han dado por el efecto de "bola de nieve", es decir, es el proceso investigativo llamado así por analogía al fenómeno. Así, apoyados en esta estrategia propuesta por Taylor y Bogdan (1996) se llega a los informantes a través de amigos en común, de conocidos que me permiten el acercamiento a personajes que nos hacen participes de sus vidas, de sus imaginarios de ciudad, situación que permite nutrir el proceso investigativo. Y con ellos se han podido sostener algunas conversaciones, entrevistas semi-estructuradas y en profundidad alrededor de tópicos sobre los cuales la teoría formal y algunas sospechas han permitido indagar alrededor de sus imaginarios de ciudad.

Estos encuentros nos han traído diálogos fluidos en el que ellos y ellas se sientan libres de comentar sus experiencias en esta ciudad, además de su relación con los recuerdos de sus lugares de procedencia; y tan sólo contrapreguntando en los aspectos que causan en el interlocutor emociones que las hacen piel, gesto, acento o emoción, otro de los elementos. Llama la atención al ubicar un presente tempo-espacial, que no es más que la suma de su pasado, la realidad de su presente y los anhelos puestos a futuro. Todo lo anterior ha permitido la emergencia de los siguientes planteamientos.

\section{Primeras impresiones}

Teniendo en cuenta que esta interpretación de las realidades de las/los jóvenes migrantes se apoya teóricamente en las "artes de hacer" propuestas por De Certeau (2000). Que son esas prácticas sociales, creativas, que se encuentran por fuera de la enseñanza institucional, las cuales no constituyen un conglomerado de reglas programadas que aseguren su repetición y su verificación, y que al contrario emergen naturalmente en la cotidianidad de su diario vivir, en sus desplazamientos por la ciudad, en el transcurrir de sus pasos por sus calles, por los sitios que ocupan, que recorren, en fin en sus tácticas y estrategias. Elementos situacionales que para este estudio permiten dar cuenta de las construcciones imaginarias que se traducen en actos de los jóvenes migrantes sobre la ciudad de Popayán.

El intento interpretativo se dirige entonces a ubicar los aportes de los jóvenes migrantes en sus relaciones de poder en dos grandes categorías propuestas por De Certeau (2000). Una, la "estrategia", la cual hace alusión al cálculo de relaciones de fuerza, cuando el sujeto es susceptible de aislarse de un ambiente, realizando una práctica en un espacio propio; y la segunda, la "táctica", que hace referencia a un cálculo dependiente del tiempo que no puede contar con un lugar propio, y ésta no tiene más lugar que el del otro. Elementos que resultan importantes al permitir establecer una radiografía del interior de los entramados sociales en los que estos jóvenes, que vienen de otros lugares, de otros espacios, encuentran en una ciudad como Popayán, una urbe con dinámicas diferentes, que les ofrece resistencia pero que también les permite moverse a su propio ritmo, para así construir sus imaginarios de ciudad. Con lo anterior, se han establecido las siguientes:

\section{Estrategias}

Manifiestan los jóvenes que la ciudad de Popayán les provee un espacio de liberación, 
como lo dice Hurtado (2011) refiriéndose a la ciudad como espacio que posibilita "Espacios de libertad en los que pueden hacer lo que quieren y lo pueden hacer por gusto, en los que pueden alcanzar el máximo nivel de actuación o de performance" (p.107). Y son estos en los que ellos y ellas pueden expresarse naturalmente, alcanzando su propio reconocimiento, el cual es representado en su forma de vestir y de hacer, modos o cosas que tal vez antes no se podían comunicar, pero que ahora en este lugar se materializan en un imaginario de libertad.

La gente, por lo que también es pueblo se deja guiar por la sociedad, que uno siempre con la misma ropa, entonces uno iba por halla, no salía porque no tenía más y entonces tendían como a criticarlo a uno que no tiene plata, acá uno anda a veces con la misma ropa y nadie le dice nada, la gente está más pendiente de las otras personas que qué tiene, que qué no, ahora ya no le paro bolas a eso, visto normal. En el pueblo si eso era algo molesto, la gente ya sabía quiénes eran los de plata por la coca y todo eso (Brayan, joven informante).

El anterior relato puede comprenderse como la capacidad de aislarse del propio espacio, prevaleciendo su propia elección ante la marejada de posibilidades preexistentes; además representa, en su lenguaje corporal, una cierta tranquilidad al mencionar el presente, su presente en Popayán.

Esta ciudad ha permitido la superación de obstáculos que les ha hecho llegar a estabilidades en el amor, en su desarrollo profesional, en su capacidad económica; les ha proveído prestigio y les ha dado el equilibrio que buscaban en los espacios de su vida; es así que este lugar ya no lo creen solamente como una ciudad a la que llegaron, sino que se ven como parte de la energía que mueve a Popayán, y es más, expresan que se sienten, en algunos casos, más payaneses que las personas nacidas aquí.

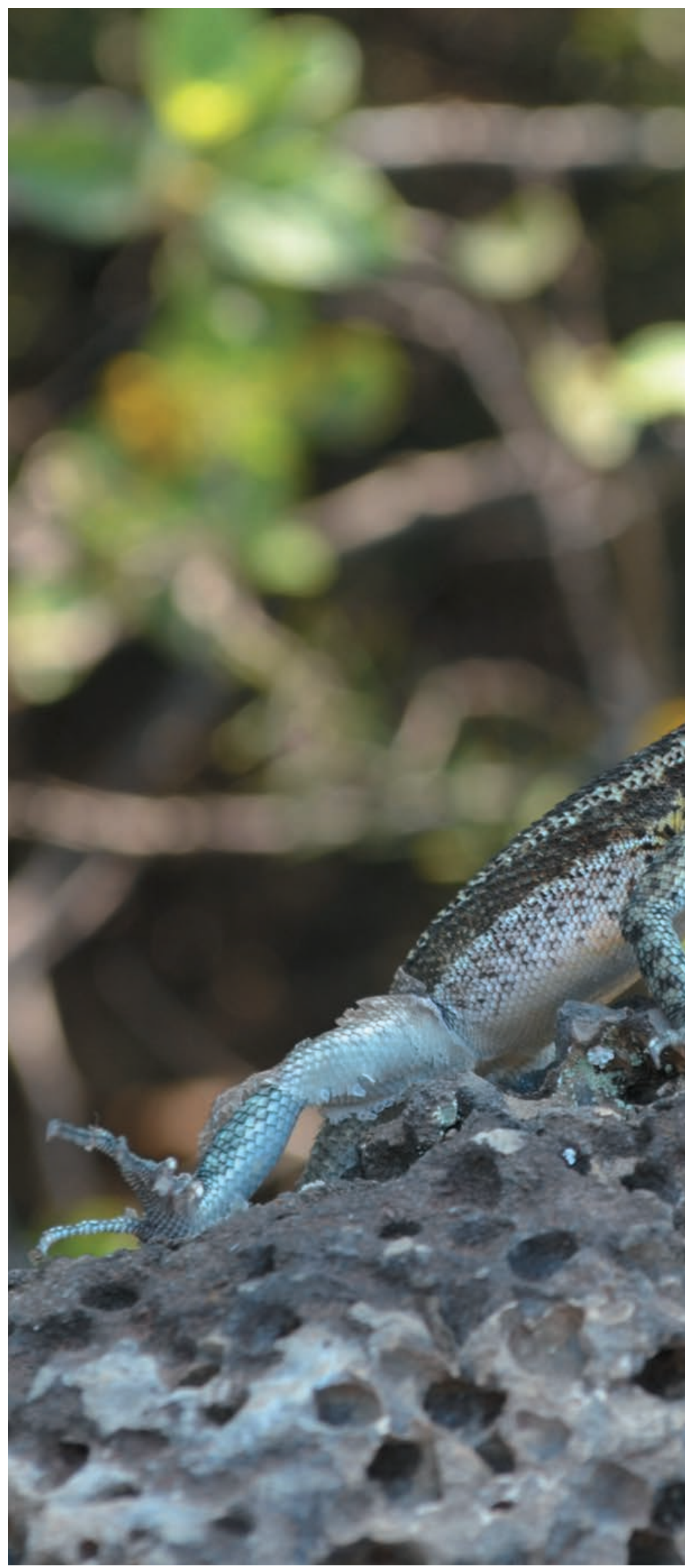


Con mi esposa, mi esposa la conocí aquí en Popayán vamos para tres años de casados, cuatro de conocernos y con ella es que vivo, vivo y convivo. Pero ahora también me la paso en la casa de mi papá porque yo me los trage a todos para acá, esta ciudad me lo ha dado todo mi profesión, mi trabajo, mi familia (Diego, joven informante).

Situaciones que muestran el impacto del espacio como escenario que carga de sentido la vida de los jóvenes, haciendo que los lugares de la ciudad de Popayán adquieran significado por lo que se hace o por lo que se comparte en ellos; en otras palabras lo hacen suyo, como lo muestra Buendía (2006) "Quienes habitan la ciudad son transformados por esta, al tiempo que ejercen sobre ella una dinámica transformadora que la construye al darle sentido, (...). Cuando se le dota de significado la ciudad deja de ser un simple espacio construido y habitado por los seres humanos y se convierte en un territorio" (p.38).

\section{Tácticas}

En cuanto a los modos de comunicación verbal, el migrante encuentra diferencias, en unos casos más marcadas que en otros, dependiendo de su procedencia; aunque el adecuarse a las muletillas y a la acentuación que comúnmente se usa en la ciudad es un proceso casi inevitable y sin esfuerzo, poco a poco las/los jóvenes han ido adoptando las expresiones verbales propias de la zona, una de las razones que les permite sentirse parte de Popayán, y de alguna manera volverse una pieza de ella, y esto dicen sentirlo mucho más cuando se confunden en la multitud de quienes viven aquí; ya no resaltan sino que hacen parte.

No directamente, pero tal vez los pelados de aquí son como gomelos, más abiertos a la gente en su forma de hablar, en su forma de ser; en cambio, cuando uno viene de otras partes, por ejemplo de un pueblo, es más tímido, empieza la gente a criticarlo; entonces, por eso es que uno queda todo callado; 


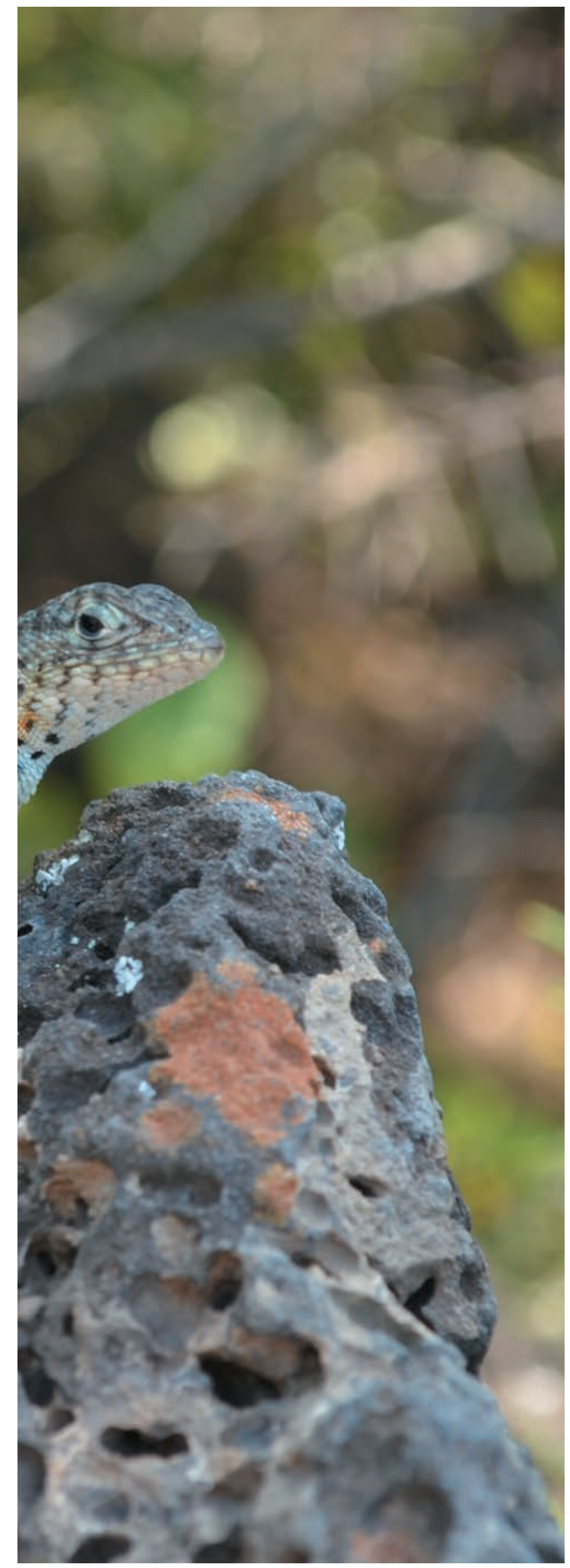

pero ya después que uno coja confianza, ya" (Brayan, joven informante).

Estas situaciones que se presentan son el cambio de los sentimientos que producen, o mejor producían, la relación con ciertos espacios, lugares de su infancia, de su procedencia que, al principio de sus desplazamientos producían añoranzas, ausencias, y que ahora tan sólo hacen parte de sus recuerdos, y éstos (los lugares) han sido remplazados por los espacios que habitualmente ocupan en esta ciudad, la cual modifican con sus recorridos y trayectos por ella, haciendo que sus relatos estén cargados de agrado al contar lo que hacen en ella, y, por lo tanto, de gran gusto al compartirlos con sus amigos.

Es que uno en el pueblo es como más ingenuo de las cosas; a veces uno va allá, siempre lo mismo; en cambio, acá hay cosas diferentes, hay eventos, mas eventos hay acá, porque allá siempre era lo mismo, los sábados la gente que bajaba de las veredas, los sábados era ir a jugar máquinas era el único juego que uno tenía los sábados; de noche no salía porque allá era peligroso, donde los abuelos, a la finca, lo básico; en cambio, uno acá sale a centros comerciales, cosas diferentes, eventos que hay cada rato. Antes iba a las fiestas del pueblo con ansiedad pero ahora ya casi ni voy ya no encuentra que hacer allá" (Maicol, joven informante).

Planteamientos que están impregnados de buenos recuerdos de sus sitios de origen, pero también están mezclados con la idea de que ese lugar del cual provienen resulta ajeno; ya no conocen los sitios de moda, no los reconocen las nuevas generaciones, se presenta una sensación de estar desubicados, de no hacer parte de él. Otro de los elementos importantes para resaltar es el valor que adquieren los espacios, como en las canchas de fútbol o microfútbol del barrio Bellohorizonte, que son escenarios en los que convergen jóvenes no sólo del barrio y de la comuna, ya que en oca- 
siones llegan a abarcar personas venidas de muchos sitios de la ciudad, situación que hace que el impacto de este trabajo se amplíe fuera del barrio para el cual fue pensado.

Durante el partido escucho diferentes acentos, palabras que no se escuchan a menudo por aquí; luego, al final del mismo, me doy cuenta que hay entre los jugadores uno de Bucaramanga, otro de Piendamó y uno de Bolívar; además, también hay jóvenes de los barrios vecinos a Bellohorizonte" (Diario de campo 2).

Argumentos que puestos en contexto nos hablan del poder de los espacios como mediadores de la dinámica social en la que los jóvenes migrantes se ven abocados a afrontar, haciendo que sus recorridos por la ciudad estén cargados de reconocimiento, identificación y singularidad.

\section{Resultados y conclusiones}

En la ciudad de Popayán se presenta una mayor libertad de vestirse a su gusto, hablar con tranquilidad, andar como se quiere y expresar lo que de verdad se quiere ser; la ciudad se muestra como un medio en el cual no se sufren señalamientos y no existe el qué dirán, uno de los imaginarios que tal vez permite que ellos con su andar transformen esta ciudad, como lo menciona Buendía (2006) “En ella se mezclan los sueños, los imaginarios, las relaciones sociales, las expresiones artísticas y estéticas de las gentes; en últimas, su cultura" (p.39). Una Popayán de apariencia educativa, de tonos blancos y con aroma de velas religiosas, convertida en otra que va más allá, dotándola de su cultura, esa que viene de sus lugares de origen, de sus familias, de las cosas que han vivido, de los caminos recorridos, de los espacios que los han hecho ser lo que son, de sus gustos y de lo que pueden ser.

Menos descomplicado, lo avispa también a uno la ciudad; la gente es diferente, se puede relacionar uno mejor, me han quitado otras costumbres del peinado, todo eso, que ahora me gusta así, más normal, y qué más, y eso no más (Brayan, joven informante).

Se presenta una oposición entre lo propio, la cultura de la cual proviene cada joven, con lo que le ofrece, le enseña y le provee la ciudad; "los primeros días sí me dio duro, casi no conocía a nadie; ya en once fue que hice más amigos; yo estaba aburrido, me quería venir de una, pero después ya no" (Maicol, joven informante). $Y$ dice también Diego, (joven informante).

Al principio, en la iglesia de Santo Domingo, donde queda la facultad de derecho, yendo para el Anarcos, la casa como es tan alta, como que me perdía, yo sentía como que me extraviaba, ya sabía dónde estaba pero como que me perdía, pero así es que uno conoce la ciudad caminándola, que el Morro, que el Pueblito Patojo, igual como todo está ahí, esa es la única forma de conocer la ciudad y saber donde están ubicadas las cosas.

Promoviéndose así un movimiento sinérgico que esculpe en cada uno, en el joven y la ciudad, rasgos propios del otro. Es una relación constante de poderes, en la que los jóvenes esperan triunfar consiguiendo sus sueños y venciendo las dificultades a su propio ritmo y a su gusto.

\section{Referencias bibliográficas}

Alcaldía de Popayán. (2012). Recuperado de http://www. popayan-cauca.gov.co/nuestraalcaldia. html

Buendía, A. (2006). Jóvenes, radio y ciudadanía. Popayán: Axis Mundi.

Castellanos, J. M. (2011). Capítulo VII La condición juvenil: opciones metodológicas para la construcción de un objeto de conocimiento. En G. Muñoz. Jóvenes, culturas y poderes (pp.161-188). Manizales: Siglo del Hombre Editores. 
Castoriadis, C. (1992). Entrevista de la colección Grandes pensadores del siglo XX. Recuperado de http://wwwyoutube.com/watch? $v=d b q X i j 8 b 2 R s$

CICR. (2012). Situación Humanitaria. Informe de Actividades Colombia 2011.Bogotá: Pro-Offset Editorial S.A.

Codhes. (2011). Consultoría para los derechos humanos y el desplazamiento. Sobre desplazamiento y conflicto armado en Colombia, primer semestre de 2011 (Número 78). Recuperado de http://www.codhes.org

Dane. (2005). Departamento administrativo nacional de estadística. Censo. Recuperado de http://www.dane. gov.co

Daza, A. (2010). La institución educativa La Milagrosa y el barrio Bello Horizonte. [Más allá de la ciudad blanca Popayán]. Recuperado de. docs.google.com/file/d/0 B2newGI1 pbpkZTY3NDFiMGQtYzNkYi00ZjJlLWEzMj EtN2RmYTAzZjl5MTBk/edit?hl=es

De Certeau M. (2000). La invención de lo cotidiano 1 Artes de hacer. Recuperado de http://www.minipimer. tv/txt/30sept/De\%20Certeau,\%20Michel\%20La\%20 Invencion\%20de\%20Lo\%20Cotidiano.\%201\%20 Artes\%20de\%20Hacer.pdf

Escobar, D., Ortega R., y Velasco H. (2007). La configuración de imaginarios de deseo en jóvenes urbanos de la ciudad de Popayán. Universidad del Cauca, Popayán, Colombia.

Feixa, C. (1999). De jóvenes, bandas y tribus. Antropología de la juventud. Barcelona: Ariel.

Freire, P. (1988). Capítulo VIII. La alfabetización como elemento de formación de la ciudadanía. En Oficina regional de educación para América Latina y El Caribe, Alternativas de educación en América Latina y el Caribe (pp.327-329). Recuperado de http://unesdoc.unesco. org/images/0008/000804/080406so.pdf

Galeano, M. (2008). Diseño de proyectos en la investigación cualitativa. Medellín. Universidad Eafit.

Hurtado, D. R. (2004). Reflexiones sobre la Teoría de Imaginarios. Una posibilidad de comprensión desde lo instituido y la imaginación radical. Cinta de Moebio, (21). Recuperado de http://www.moebio.uchile. $\mathrm{cl} / 21 /$ frames05.htm

(2011). Entramados. Jóvenes y configuraciones de significaciones imaginarias de deseo. Popayán. Rudecolombia.
Margulis, M., Urresti M. (1998). La construcción social de la condición de juventud. En H. J. Cubides (Ed.), Viviendo a toda. Jóvenes, territorios culturales y nuevas sensibilidades (pp.3-21) Bogotá: Siglo del hombre editores.

Martín, J. (2002). La educación desde la comunicación. Enciclopedia Latinoamericana de sociocultura y comunicación. [Medio escrito]. Buenos Aires. Editorial Norma.

Martínez, J. E. (2011). Capítulo VIII Subjetividad, política y multitud: tres referentes para abordar la juventud. En G. Muñoz. Jóvenes, culturas y poderes (pp.189-219). Manizales: Siglo del Hombre Editores.

Muñoz, G. (2011). Capítulo II La relación de los jóvenes y las jóvenes con la cultura y el poder. En G. Muñoz. Jóvenes, culturas y poderes (pp.43-64). Manizales: Siglo del Hombre Editores.

Portes, A. (2001). Inmigración y metrópolis: reflexiones acerca de la historia urbana. Migraciones Internacionales. Redalyc, 1. (1). Recuperado de http://redalyc. uaemex.mx/pdf/151/15100106.pdf

Reguillo, R. (1995). Pensar la ciudad desde la comunicación. Un ejercicio necesario. En J. Galindo, (Ed.), Campos académicos de la comunicación: hacia una reconstrucción reflexiva (pp.109-132). México: CONACULTA.

Restrepo, B. (2002). Investigación en educación. Bogotá: ARFO.

Taylor, S. J. \& Bogdan, R. (1996). Introducción a los Métodos Cualitativos de Investigación. Barcelona: Paidós.

Tocancipá, J. (2006). Cafés en la 'ciudad blanca': identidad, crisis cafetera y el restablecimiento del orden social en Colombia. Dialnet (25). Recuperado de http:// dialnet.unirioja.es/servlet/articulo?codigo $=2348413$

Trilla, J. (1993). Otras Educaciones. Animación sociocultural, formación de adultos y ciudad educativa. Barcelona: Antropos.

Ulloa, A (2000). Globalización, Ciudad y representaciones Sociales. El caso de Cali. Medellín: Universidad Pontificia Bolivariana.

Vasco, C (1997). Algunas reflexiones sobre la pedagogía y la didáctica. Pedagogía discurso y poder. Recuperado de http://ineduga.webcindario.com/pedagogiadidactica.pdf 